\title{
BIONOMÍA DE LAS ESPECIES DE PHYLLOPHAGA (COLEOPTERA: MELOLONTHIDAE) EN SANTA CRUZ XOXOCOTLÁN, OAXACA, MÉXICO
}

\author{
Julián HERNÁNDEZ-CRUZ, ${ }^{1}$ Miguel Ángel MORÓN, ${ }^{2 *}$ JaIMe RUIZ- \\ VEGA, ${ }^{1}$ JosÉ ANTONIO SÁNCHEZ-GARCÍA, ${ }^{1}$ LAURA MARTÍNEZ- \\ MARTÍNEZ ${ }^{1}$ \& RAFAEL PÉREZ-PACHECO ${ }^{1}$ \\ ${ }^{1}$ Instituto Politécnico Nacional. CIIDIR Unidad Oaxaca. Hornos 1003, Col. Nochebuena. Sta. Cruz \\ Xoxocotlán, Oaxaca 71230, México. $<$ jhcciidir@yahoo.com.mx> \\ ${ }_{2}^{2}$ Instituto de Ecología A.C. Carretera Antigua a Coatepec 351, El Haya, Xalapa, Veracruz. 91070, \\ México. *autor corresponsal: <miguel.moron.@inecol.edu.mx>
}

Hernández-Cruz, J., Morón, M. A., Ruiz-Vega, J., Sánchez-García, J. A., Martínez-Martínez, L., \& Pérez-Pacheco, R. 2014. Bionomía de las especies de Phyllophaga (Coleoptera: Melolonthidae) en Santa Cruz Xoxocotlán, Oaxaca, México. Acta Zoológica Mexicana (n.s.), 30(1): 144-160.

RESUMEN. Se presentan los resultados de las colectas con trampas de luz fluorescente y colectas manuales directas de especies de Phyllophaga, efectuadas entre abril 2009 y julio 2010 en dos sitios de Santa Cruz Xoxocotlán, Oaxaca, ubicados a $1550 \mathrm{msnm}$. Se capturaron representantes de 13 especies: Phyllophaga lenis (Horn), P. macrocera (Bates), P. nubipennis (Bates), P. parvisetis (Bates), P. cinnamomea (Blanchard), P. ravida (Blanchard), P. misteca (Bates), P. vetula (Horn), P. obsoleta (Blanchard), P. scabripyga (Bates), P. chiapensis (Chapin), P. porodera (Bates) y P. integriceps (Moser). El grupo de especies con mayor número de representantes fue "anodentata" con cinco especies. La especie más abundante fue $P$. lenis, con 3,107 de los 3,251 ejemplares capturados durante los dos años. Se incluye una clave para identificar los machos de las 13 especies, así como fotografías de las estructuras diagnósticas para cada especie.

Palabras clave: Escarabajos de mayo, taxonomía, riqueza de especies, ambiente subtropical.

Hernández-Cruz, J., Morón, M. A., Ruiz-Vega, J., Sánchez-García, J. A., Martínez-Martínez, L., \& Pérez-Pacheco, R. 2014. Bionomics of the species of Phyllophaga (Coleoptera: Melolonthidae) in Santa Cruz Xoxocotlan, Oaxaca, Mexico. Acta Zoológica Mexicana (n.s.), 30(1): 144-160.

ABSTRACT. Results of collecting made with fluorescent light traps and by hand between April 2009 and July 2010 in two sites of Santa Cruz Xoxocotlán, Oaxaca are presented. These sites are located at $1550 \mathrm{~m}$ of altitude. Thirteen species were collected: Phyllophaga lenis (Horn), P. macrocera (Bates), $P$. nubipennis (Bates), P. parvisetis (Bates), P. cinnamomea (Blanchard), P. ravida (Blanchard), P. misteca (Bates), P. vetula (Horn), P. obsoleta (Blanchard), P. scabripyga (Bates), P. chiapensis (Chapin), P. porodera (Bates) and $P$. integriceps (Moser). The species group that showed a higher species richness was

Recibido: 04/06/2013; aceptado: 04/09/2013. 
"anodentata". The most abundant species was $P$. lenis with 3107 of the 3251 specimens collected during the two years. A key for males of the 13 species is provided. Also, pictures of diagnostic structures of each species are included.

Keys words: May beetles, taxonomy, species richness, subtropical conditions.

\section{INTRODUCCIÓN}

El género Phyllophaga muestra una elevada riqueza específica en el estado de Oaxaca, lo que posiblemente es un reflejo de la irregular topografía que determina una gran diversificación de hábitats y de la gran capacidad de adaptación que tienen las especies de este género para ocupar distintos ambientes. Morón (2003) enlistó 71 especies para el Estado, y en publicaciones recientes se han agregado seis nuevos taxones (Morón \& Woodruff 2008; Morón 2008; Morón 2012; Morón \& Nogueira 2012; Morón \& Hernández-Cruz 2013). La importancia económica del género radica en que algunas de sus especies pueden dañar a diferentes cultivos, lo que disminuye su rendimiento, y de acuerdo con las experiencias locales, su control es difícil si no se emplea un programa adecuado a las condiciones de cada región, que distinga con claridad los patrones de actividad en las poblaciones de cada especie (Morón et al. 2010a).

Por lo anterior, es necesario promover trabajos que incluyan colectas de especímenes de Phyllophaga en áreas donde el género está bien representado y diversificado, hacer el estudio morfológico detallado de los mismos y construir claves regionales apoyadas con ilustraciones que faciliten el reconocimiento específico. El objetivo principal del presente estudio consiste en contribuir al conocimiento básico del género Phyllophaga en Oaxaca, mediante la determinación precisa de los adultos de las especies que habitan un área representativa de los Valles Centrales del Estado, complementada con una clave dicotómica para apoyar la identificación de las especies durante proyectos con enfoques ecológicos o agrícolas.

\section{MATERIAL Y MÉTODOS}

Características del área de estudio. La investigación se realizó en dos sitios del municipio de Santa Cruz Xoxocotlán (Fig. 1), cuya altitud es de $1560 \mathrm{msnm}$, temperatura promedio mensual mínima y máxima de 9.1 y $32{ }^{\circ} \mathrm{C}$ respectivamente y una precipitación anual que oscila entre 649 y 795 mm en los últimos dos años (2009-2010). Predomina un clima subhúmedo, semicálido (BS1h). Debido a la injerencia de los campesinos con el cultivo extensivo queda poca vegetación original. Actualmente la vegetación dominante es de tipo xerófita, asociada al chaparral, principalmente guamúchil [Pithecellobium dulce (Roxb.) Benth.], mezquites [Prosopis juliflora (Swartz) DC.], huizache [Acacia farnesiana (L.) Willd.], cactáceas, agaves y pastos. Las áreas arboladas (principalmente con pinos y encinos) o cubiertas con carrizo [Phragmites communis Trin.] son cada vez más escasas. El uso del suelo del área de 


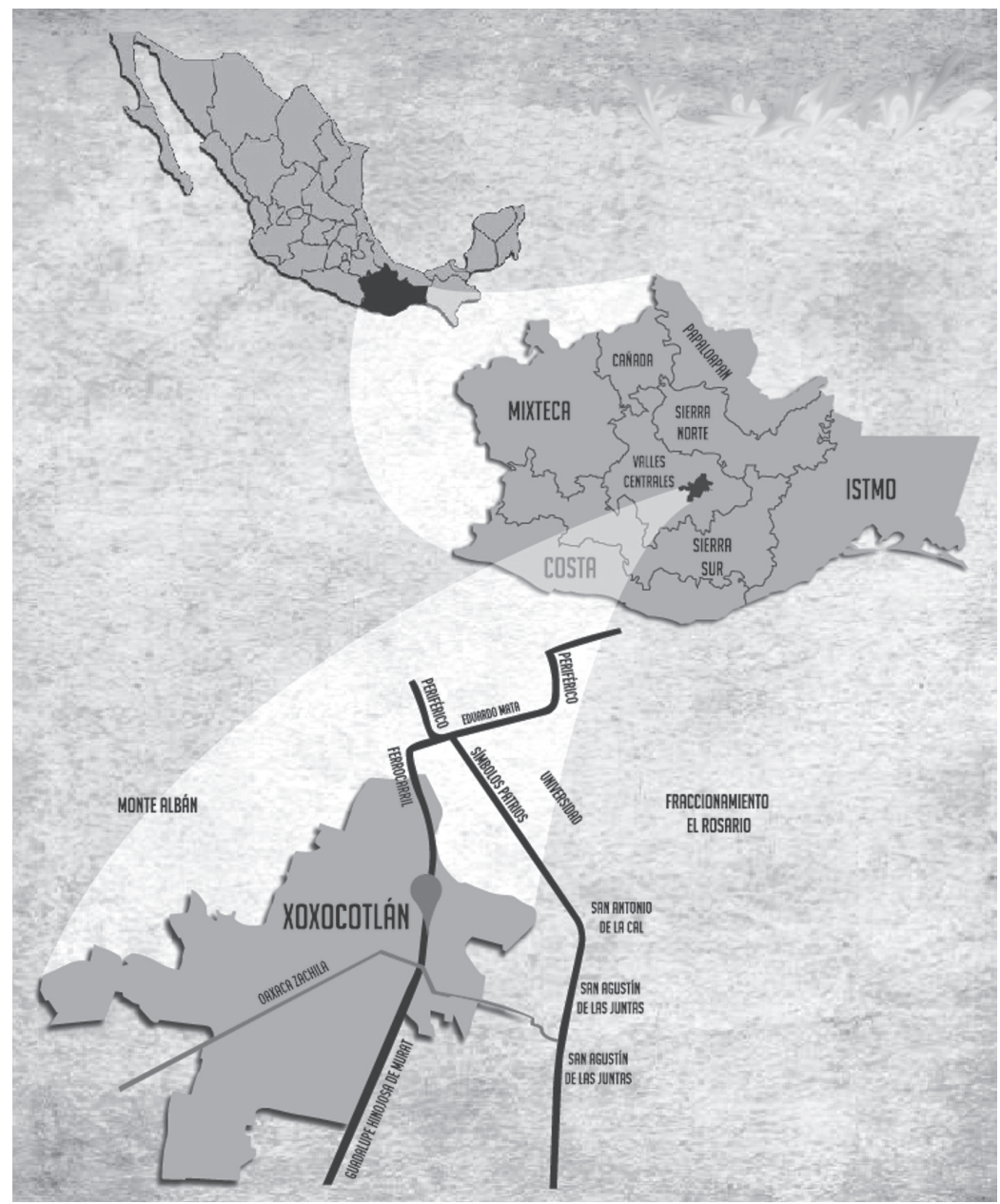

Figura 1. Zona de trabajo en Santa Cruz Xoxocotlán, región Valles Centrales de Oaxaca, México.

estudio, está destinado básicamente a dos actividades: la agricultura de temporal/riego y el pastoreo de ovinos y caprinos en menor escala. Los tipos de suelo son vertisolpélico y en menores proporciones acrisol férrico, luvisol crómico y luvisolpélico.

Se capturaron adultos del género Phyllophaga con la ayuda de trampas tipo embudo con luz fluorescente desde el mes de abril de 2009 hasta julio de 2010, operadas durante tres días del período de luna nueva de cada mes. También se colectaron manualmente en el campo los ejemplares que no fueron atraídos por la luz. Se registraron datos de abundancia y diversidad. Los ejemplares capturados se montaron junto con su respectiva genitalia siguiendo las técnicas de Morón \& Terrón (1988). 
Para identificarlos, se usaron los criterios de Morón (1986, 2006a). Posteriormente se prepararon las diagnosis de los grupos específicos correspondientes y una clave dicotómica para separar las especies. Las imágenes de las especies obtenidas y sus estructuras diagnósticas fueron captadas con una cámara digital adaptada al microscopio estereoscópico, y se usó el programa GIMP para la edición de las imágenes. Los ejemplares estudiados están depositados en las colecciones entomológicas del CIDIIR, Oaxaca y el Instituto de Ecología, A. C. Xalapa (IEXA).

\section{RESULTADOS}

Inventario de especies del área de estudio. Se obtuvieron 3,251 ejemplares que representan a 13 especies incluidas en siete grupos y tres subgéneros de Phyllophaga (Cuadro 1). La especie más abundante fue $P$. lenis que representa el $95.5 \%$ de la muestra total. Los primeros ejemplares de ésta aparecieron en la segunda quincena de marzo, generalmente después de una lluvia abundante, y emergen del suelo al empezar la noche para posarse o copular sobre el pasto, rosales, arbustos de huizache existentes en los jardines de las casas, parques municipales o en el campo. El grupo de especies que predomina en la región de estudio es "anodentata", y el subgénero que más representantes tiene es Phyllophaga (s. str.).

Ocho de las especies encontradas ( $P$. lenis, $P$. macrocera, $P$. ravida, $P$. misteca, $P$. vetula, $P$. obsoleta, $P$. porodera y $P$. chiapensis) han sido citadas frecuentemente

Cuadro 1. Número de individuos por especie de Phyllophaga (sensu lato) colectados en 2009 y 2010 en Santa Cruz Xoxocotlán, Oaxaca.

\begin{tabular}{lllc}
\hline \multicolumn{1}{c}{ Subgénero } & \multicolumn{1}{c}{ Grupo } & \multicolumn{1}{c}{ Especie } & Ejemplares \\
\hline Chlaenobia & "latipes" & P. scabripyga (Bates, 1888) & 8 \\
Chlaenobia & "latipes" & P. chiapensis (Chapin, 1935) & 7 \\
Phytalus & "obsoleta" & P. obsoleta (Blanchard, 1850) & 8 \\
Phytalus & "macrocera" & P. macrocera (Bates, 1888) & 45 \\
Phytalus & "macrocera" & P. nubipennis (Bates, 1888) & 7 \\
Phyllophaga & "porodera" & P. porodera (Bates, 1888) & 1 \\
Phyllophaga & "rorulenta" & P. parvisetis (Bates, 1888) & 36 \\
Phyllophaga & "rorulenta" & P. cinnamomea (Blanchard, 1850) & 1 \\
Phyllophaga & "ravida" & P. ravida (Blanchard, 1850) & 12 \\
Phyllophaga & "anodentata" & P. lenis (Horn, 1887) & 3107 \\
Phyllophaga & "anodentata" & P. vetula (Horn, 1887) & 8 \\
Phyllophaga & "anodentata" & P. misteca (Bates, 1888) & 10 \\
Phyllophaga & "anodentata" & P. integriceps (Moser, 1918) \\
Total 3 & $\mathbf{7}$ & & $\mathbf{1 3}$ \\
\hline
\end{tabular}


en ambientales agrícolas de 1993 a la fecha y casi todas (a excepción de la última) tienen hábitos rizófagos en su estado larvario (Morón 2010). Sólo se han estudiado con detalle los estados larvarios de cinco de las especies incluidas en este estudio ( $P$. lenis, $P$. macrocera, $P$. ravida, $P$. vetula y $P$. obsoleta) (Ramírez-Salinas et al. 2000; Aragón \& Morón 2004; Hernández-Cruz 2010). Del total de especies colectadas sólo para seis ( $P$. macrocera, $P$. ravida, $P$. misteca, $P$. vetula, $P$. obsoleta y $P$. parvisetis) se ha descrito el ciclo vital completo que es anual con excepción de la última que requiere dos años (Aragón et al. 2005).

Con base en los resultados obtenidos en este estudio y lo documentado por Morón (2006b) se observa que cuando se estudian las comunidades de Phyllophaga de una región del país, es común que en ellas existan especies sobre las cuales se han logrado avances sustanciales en el conocimiento de su biología, fenología, ecología, taxonomía, etc., pero también existen otras sobre las cuales no se ha documentado suficiente información de este tipo y quizá esto se deba a que no representan un problema o cuya presencia resulte rara e intrascendente.

Tal indiferencia hacia este tipo de especímenes puede resultar a veces de alto riesgo. Al respecto, existe un caso bien documentado (Morón et al. 1996, Morón et al. 1999, Morón 2006b y Morón et al. 2010b) acerca de Phyllophaga lalanza. Esta especie no parecía tener una adaptabilidad ecológica interesante, ni una distribución significativa y aparentemente no representaba una amenaza para los cultivos en Nayarit y Jalisco, pero a partir de 1996 se constituyó en una de las plagas más voraces y con un predominio tal, que su expansión poblacional fortalece la hipótesis sobre el potencial que tiene cualquier insecto fitófago de constituirse en una plaga. Por ello, como lo mencionan Morón et al. (2010b) nunca estará de más el estudiar una especie y reunir toda la información posible acerca de su taxonomía, biología, ecología, fenología, hospederos y enemigos naturales.

A continuación se presenta una diagnosis de los grupos presentes en este estudio, seguida de una clave dicotómica para separar las especies, relacionada con las imágenes que se presentan al final.

\section{Diagnosis de los grupos}

Latipes. Este grupo incluye especies cuya longitud oscila entre 11 y $17 \mathrm{~mm}$. Antenas formadas por 10 artejos, el $4^{\circ}$ artejo más corto que el $3^{\circ}$. Maza antenal masculina con longitud variable de acuerdo a la especie, tan larga o un poco mayor que el funículo. Labro reniforme, setífero o glabro. Pronoto brillante, con puntuación fina, moderada, en ocasiones densa o ligeramente rugosa. Ángulos posteriores del pronoto poco obtusos o casi rectos, doblados o replegados hacia el pleuron. Pigidio masculino generalmente glabro, en algunas especies tiene una cobertura de sedas largas abundantes y en otras con sedas cortas esparcidas. Pigidio femenino generalmente excavado, surcado o tuberculado, generalmente glabro. Placa anal masculina con forma varia- 
ble, excavada o casi plana, amplia o estrecha y con sedas abundantes o escasas. Placa anal femenina convexa y amplia. Todos los artejos tarsales masculinos mayor o menormente ensanchados o deprimidos, provistos de una abundante cobertura setífera bastante densa y evidente en sus partes ventrales (Morón 1986).

Obsoleta. Las especies que conforman este grupo tienen el cuerpo ovalado y robusto con longitud de 16 a $24 \mathrm{~mm}$, coloración parda rojiza o parda amarillenta brillante y el pronoto es más ancho que la cabeza. Se caracterizan por la presencia de antenas formadas por 10 artejos; los artejos $3^{\circ}$ a $5^{\circ}$ Cortos; maza antenal masculina más larga o de igual longitud que el funículo; clípeo subtrapezoidal redondeado; pronoto y élitros glabros; espolones metatibiales libremente articulados en ambos sexos; dentículo inferior de las uñas tarsales más largo que el dentículo superior o con igual longitud que éste; usualmente el dentículo superior es más estrecho que el inferior; borde interior de las uñas fino o muy finamente aserrado; placa pigidial en los machos más o menos convexa; vestidura pigidial escasa o ausente; placa anal masculina corta y ligeramente escavada o acanalada mesialmente (Morón 1986, 2006a).

Macrocera. Las especies incluidas en este grupo tienen una longitud entre 13 y 18 mm. Cuerpo ovalado. Color pardo oscuro, rojizo o amarillento. Antenas formadas por diez artejos ( $3^{\circ}$ a $5^{\circ}$ Cortos). Maza antenal masculina más larga o de igual longitud que el funículo. Maza antenal femenina de igual longitud que el funículo. Clípeo subrectangular o redondeado. Pronoto y élitros setíferos, ligeramente aterciopelados o glabros. Pigidio masculino moderadamente convexo. Vestidura pigidial escasa o nula. Placa anal masculina convexa, excavada o surcada. Espolón metatibial externo masculino libremente articulado con el borde de la tibia. Proyección inferior del ápice de las uñas tarsales más corta que la proyección superior. Borde inferior de las uñas liso o aserrado (Morón 1986).

Porodera. Las especies de este grupo tienen una longitud entre 14 y $19 \mathrm{~mm}$. Cuerpo ovalado, robusto, notablemente ensanchado hacia atrás. Color castaño oscuro a castaño rojizo, con un toque blanquecino o grisáceo. Región dorsal aterciopelada, con sedas erectas medianamente esparcidas. Cabeza pequeña en proporción con el protórax, ojos pequeños y poco prominentes. Clípeo corto, redondeado y ligeramente sinuado. Antenas formadas por nueve artejos. Maza antenal masculina de igual longitud que el funículo. Labro pequeño, reniforme, ampliamente sinuado. Pronoto 1.5 veces más ancho que largo, con los bordes laterales redondeados poco proyectados en su porción media; puntuación circular, amplia y moderadamente densa; ángulos anteriores prominentes y aguzados; ángulos basales obtusos, bien marcados. Pigidio masculino poco convexo, con cobertura setífera abundante y mixta. Placa anal masculina estrecha, excavada, con un reborde posterior sinuado o escotado. Vestidura mesial de los esternitos escasa, corta y fina sobre una cubierta aterciopelada. Ambos espolones metatibiales masculinos articulados. Uñas masculinas con el dentículo intermedio corto, semitriangular y más o menos equidistante de los extremos. Parámeros cortos, 
fusionados en anillo. Edeago con soporte esclerosado, muy ornamentado con placas y grupos de sedas macroscópicas simétricas (Morón 1986).

Rorulenta. Las especies de este grupo tienen una longitud entre 16 a $26 \mathrm{~mm}$. Cuerpo alargado, robusto, claramente ensanchado hacia atrás. Color castaño rojizo o castaño oscuro, brillante o mate. Región dorsal con cubierta aterciopelada blanquecina, y en ocasiones con sedas erectas esparcidas o casi totalmente glabra. Cabeza grande en proporción con el protórax, pero pequeña en relación con el cuerpo; ojos grandes poco prominentes. Clípeo corto, redondeado, ligera o acentuadamente bilobulado, con el seno mesial poco marcado o casi escotado, provisto de puntuación densa. Antenas formadas por diez artejos. Maza antenal masculina ligeramente más larga que el funículo. Maza antenal femenina menor que el funículo. Labro profundamente bilobulado, setífero y prominente. Pronoto 1.5 veces más ancho que largo, con los bordes laterales poco proyectados en su parte media; puntuación bien marcada, pequeña e irregularmente distribuida; ángulos posteriores obtusos pero bien marcados. Pigidio masculino poco convexo; placa anal masculina muy estrecha, transversalmente excavada con carina en el borde anterior. Vestidura media de los esternitos escasa o casi nula. Espolón metatibial externo masculino fusionado con el borde apical y más corto que el que el espolón interior. Uñas masculinas con el dentículo intermedio tan largo como el dentículo apical o mayor que este, ampliamente separado de ambos extremos, con la dilatación basal pequeña y redondeada. Parámeros cortos, compactos fusionados ventro-basalmente. Edeago poco esclerosado sin ornamentación macroscópica compleja, pero con abundantes microespinas (Morón 1986).

Ravida. Las especies de este grupo tienen una longitud entre 12 a $14 \mathrm{~mm}$. Cuerpo alargado, un poco ensanchado hacia atrás. Color amarillento o pardo rojizo. Región dorsal brillante, con frecuencia cubierta con sedas variables en longitud, distribución y densidad. Cabeza pequeña en proporción con el protórax; ojos grandes poco prominentes. Clípeo trapezoidal redondeado, cóncavo con puntuación variable. Antenas formadas por diez artejos. Maza antenal masculina dos veces mayor que el funículo. Labro reniforme, estrecho y poco prominente. Pronoto ligeramente más ancho que largo, con los bordes laterales poco proyectados en su porción media; puntuación pequeña pero bien marcada con densidad y distribución variable; ángulos posteriores casi rectos y un poco proyectados, o ligeramente obtusos y redondeados. Pigidio masculino convexo prominente hacia el ápice con vestidura variable pero siempre presente. Placa anal masculina someramente excavada, acanalada o casi plana. Vestidura mesial de los esternitos escasa o abundante. Ambos espolones metatibiales articulados. Uñas con la base dilatada y el diente intermedio largo y afilado, flanqueado por escotaduras profundas, o corto y desplazado cerca de la dilatación basal. Las uñas exteriores de los mesotarsos masculinos presentan la porción apical recurvada, de tal modo que el diente intermedio sobresale lateralmente deformando el conjunto. Parámeros cortos y fusionados disto-ventralmente. Edeago ornamentado con sedas largas 
y gruesas, o con un soporte esclerosado voluminoso (Morón 1986).

Anodentata. Las especies de este género tienen una longitud entre 13 y $20 \mathrm{~mm}$. Cuerpo ovalado, robusto, ensanchado hacia atrás. Color pardo obscuro, pardo rojizo, castaño rojizo, castaño amarillento y frecuentemente con toque grisáceo o blanquecino. Región dorsal cubierta con sedas largas y cortas abundantes, más notorias en la región anterior y en ocasiones con una cubierta aterciopelada fina. Clípeo corto, redondeado, casi hemicircular, en ocasiones con el borde anterior ligeramente sinuado. Antenas con diez artejos. Maza antenal masculina de igual longitud que el funículo o hasta dos veces más larga que este. Pronoto 1.5 veces más ancho que largo, con los bordes laterales moderadamente proyectados en su porción media; puntuación en general circular, fina y densa, setífera, aunque en ocasiones es tosca; ángulos anteriores prominentes y aguzados o poco notables y redondeados; ángulos posteriores obtusos pero bien marcados. Pigidio masculino poco convexo. Placa anal masculina con un reborde anterior que alcanza los extremos laterales, y cuya parte medial presenta una escotadura, un seno o un proceso bilobulado o bidentado; y en otros casos este reborde solo está marcado hacia los lados. Vestidura mesial de los externitos variable, escasa a abundante, pero siempre corta y fina. Ambos espolones metatibiales articulados. Uñas masculinas con el dentículo intermedio corto, semitriangular y frecuentemente un poco aproximado hacia la pequeña dilatación basal. Parámeros cortos, fusionados en anillo, con una pequeña proyección bidentada ventral y dentículos laterodistales simétricos. Edeago esclerosado, muy ornamentado con espinas y sedas y un filamento recurvado ligeramente asimétrico en algunas especies (Morón 1986).

\section{Clave para separar las especies de Phyllophaga de Santa Cruz Xoxocotlán Oaxaca}

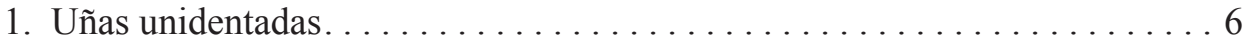

1'. Uñas bífidas o hendidas. . . . . . . . . . . . . . . . . . . . 2

2. Tarsos con abundante cobertura de sedas ventrales. Coloración pajiza. Cuerpo

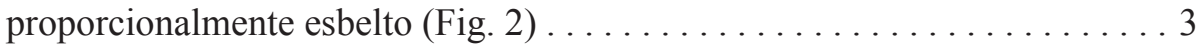

2'. Tarsos con escasas sedas ventrales. Coloración castaño oscura o amarillenta.

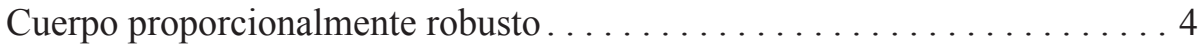

3. Especie amarillenta pajiza (Fig. 3). Espolones metatibiales superiores casi rectos. En vista distal los parámeros están ensanchados, aplanados y divergentes (Fig. 5). Los parámeros en vista lateral ensanchados en su base y delgados en su ápice (Fig. 4). Edeago sacular con un soporte esclerosado poco ornamentado (Fig. 4). Longitud corporal $15 \mathrm{~mm}$............ (Chlaenobia) scabripyga

3'. Especie amarillenta (Figs. 6 y 8). Espolones metatibiales superiores ligeramente curvados. En vista distal los parámeros adelgazados y convergentes hacia el ápice (Fig. 9), con proyecciones afiladas laterales (Figs. 7 y 9). Edeago sacular sin ornamentos grandes (Fig. 7). Longitud corporal 

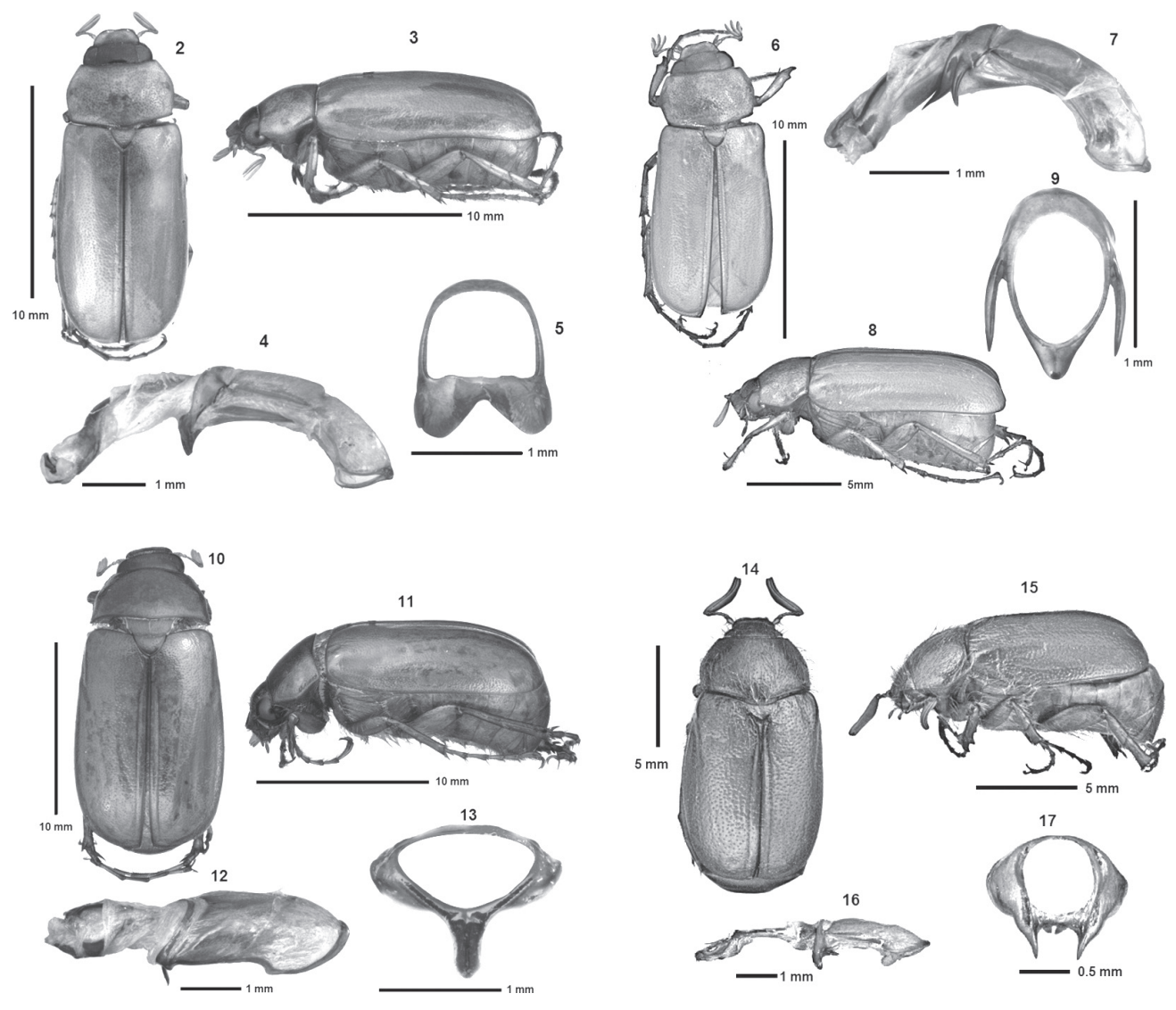

Figuras 2-17. Especies de Phyllophaga en Xoxocotlán: P. scabripyga macho, 2) vista dorsal, 3) vista lateral, 4) aspecto lateral de genitalia completa, 5) aspecto distal parámeros. P. chiapensis macho, 6) vista dorsal, 7) aspecto lateral de genitalia completa, 8) vista lateral, 9) aspecto distal parámeros. P. obsoleta macho,10) vista dorsal, 11) vista lateral, 12) aspecto lateral de genitaliacompleta, 13) aspecto distal parámeros. P. macrocera macho, 14) vista dorsal, 15) vista lateral, 16) aspecto lateral de genitalia completa, 17) aspecto distal parámeros.

$14 \mathrm{~mm} \ldots \ldots \ldots \ldots \ldots \ldots \ldots \ldots . . \ldots \ldots . \ldots \ldots$ (Chlaenobia) chiapensis

4. Machos con una placa escamosa notable en los últimos esternitos abdominales. Especies de color rojizo, aspecto dorsal glabro, brillante (Figs. 10 y 11). Hembras con un tubérculo preapical en la placa pigidial. Parámeros delgados en vista lateral, con los ápices convergentes, contiguos, orientados ligeramente hacia atrás (Figs. 12 y 13). Edeago sacular con soporte esclerosado sin ornamentos visibles (Fig. 12). En vista lateral los parámeros aplanados (Fig. 12). Longitud del cuerpo $18 \mathrm{~mm} \ldots \ldots \ldots \ldots \ldots \ldots$. (Phytalus) obsoleta 
4'. Machos sin una placa escamosa notable en los últimos esternitos abdominales o diferente a lo descrito anteriormente . . . . . . . . . . . . . 5

5. Diente inferior de las uñas mucho más corto que el superior, a veces paralelo a éste. Maza antenal notablemente más larga que el resto de los artejos (Fig. 14). Coloración parda-oscura, con abundante cobertura setífera ventral (Fig. 15). En vista distal, parámeros ensanchados en su parte media, convergentes, con proyecciones laterales afiladas orientadas hacia la parte caudal y un par de dentículos en la unión de los ápices también proyectados caudalmente (Fig. 17). Edeago esclerosado, con un proceso setífero en el ápice (Fig. 16). Hembras con la placa pigidial convexa . ...................(Phytalus) macrocera

5 '. Diente inferior de las uñas no mucho más corto que el superior y al menos un poco recurvado en los machos. Especie con superficie dorsal glabra, brillante, con abundantes sedas largas en la región pleuroventral (Figs. 18 y 19). Parámeros fusionados en su base y en vista lateral fuertemente ensanchados con proyecciones laterales ligeramente recurvadas y proyectadas proximalmente con ápices convergentes (Figs. 20 y 21). Edeago sacular sin proyecciones ni ornamentos (Fig. 20) . . . . . . . . . . . . . P. (Phytalus) nubipennis

6. Antenas con 9 artejos. Coloración parda amarillenta (Figs. 22 y 23). En vista distal, parámeros cortos, delgados, convergentes en su ápice (Fig. 25), con proyecciones laterales afiladas fuertemente orientadas hacia atrás (Fig. 24). Edeago con soporte esclerosado, con un proceso setífero largo preapical (Fig. 24). Longitud del cuerpo $14 \mathrm{~mm}$............. P. (Phyllophaga) porodera 6'. Antenas con 10 artejos. Los otros caracteres distintos a lo indicado antes . . 7

7. Espolón metatibial de los machos corto y fusionado al borde tibial . . . . . 8

7'. Espolón metatibial de los machos articulado con el borde tibial . . . . . . . 9

8. Especie de color castaño oscuro, robusta, vestidura dorsal setífera (Figs. 26 y 27). En vista distal,parámeros cortos fuertemente ensanchados en su ápice (Fig. 29) y en vista lateral muy ensanchados en su base (Fig. 28). Edeago sacular, con un pequeño soporte esclerosado, sin ornamentos visibles (Fig. 28) ......................... (Phyllophaga) parvisetis

8 '. Especie de color castaño brillante, robusta, con la superficie dorsal aterciopelada (Figs. 30 y 31). En vista distal los parámeros cortos, uniformemente delgados con proyecciones laterales semicónicas (Fig. 33) y en vista lateral, fuertemente ensanchados en su base y delgados en su ápice (Fig. 32). Edeago sacular, ligeramente ensanchado en su ápice, sin ornamentos (Fig. 32) . . . . . . . . . . . . . . . . . . . (Phyllophaga) cinnamomea

9. Machos con las uñas mesotarsales deformadas, asimétricas. Superficie dorsal glabra y brillante (Figs. 34 y 35). Parámeros cortos y ensanchados en vista lateral, con los ápices fusionados y ligeramente dirigidos apicalmente (Figs. 36 y 37). Edeago corto con un soporte bifurcado (en vista dorsal) y una espina 

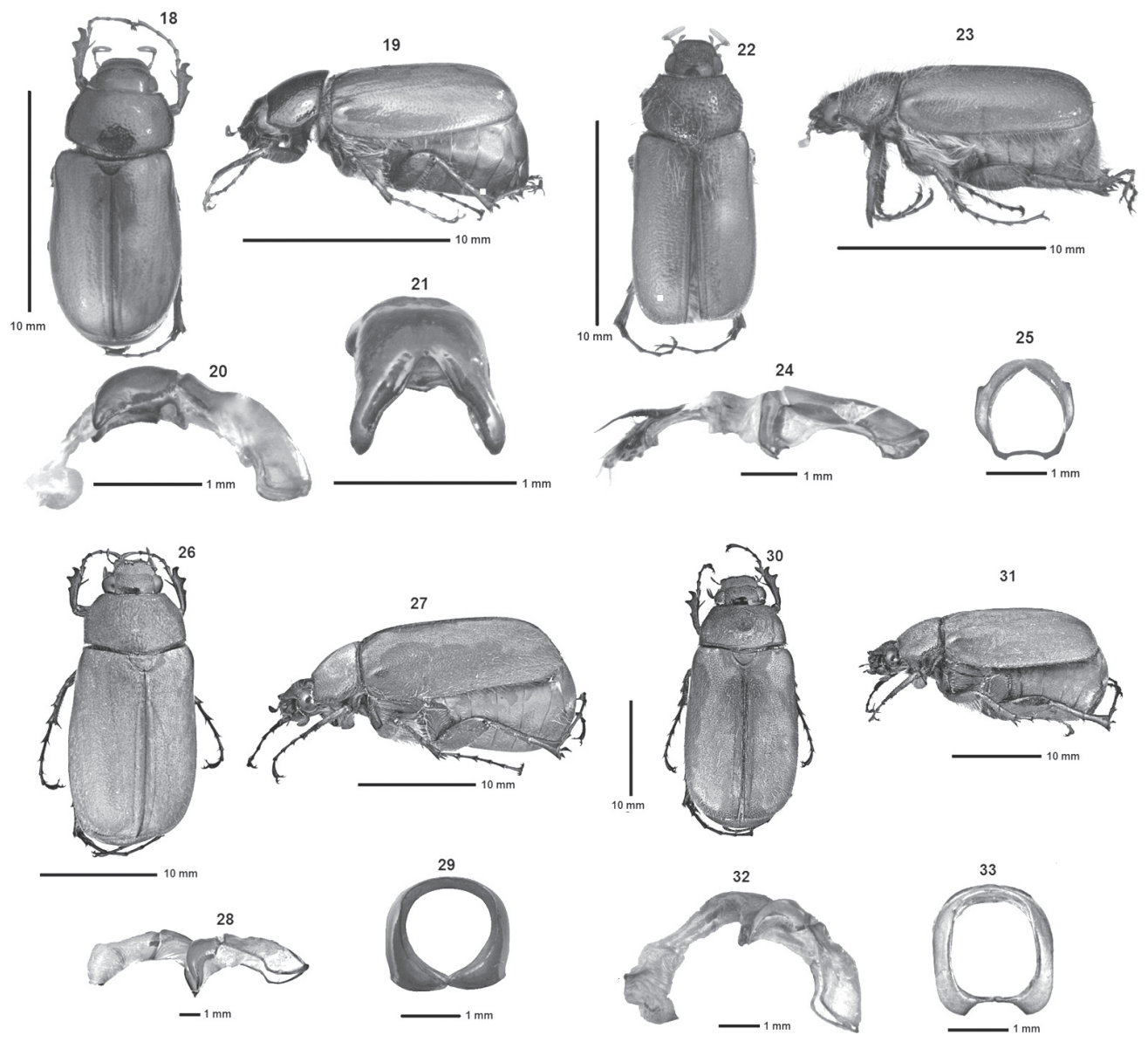

Figuras 18-33. Especies de Phyllophaga en Xoxocotlán: P. nubipennis macho, 18) vista dorsal, 19) vista lateral, 20) aspecto lateral de genitalia completa, 21) aspecto distal parámeros. $P$. porodera macho, 22) vista dorsal, 23) vista lateral, 24) aspecto lateral de genitalia completa, 25) aspecto distal parámeros. P. parvisetis macho, 26) vista dorsal, 27) vista lateral, 28) aspecto lateral de genitalia completa, 29) aspecto distal parámeros. P. cinnamomea macho, 30) vista dorsal, 31) vista lateral, 32) aspecto lateral de genitalia completa, 33) aspecto distal parámeros.

dorso apical (Fig. 36). Longitud corporal $16 \mathrm{~mm} \mathrm{....P.} \mathrm{(Phyllophaga)} \mathrm{ravida}$ 9'. Machos con uñas mesotarsales simétricas, curvas. Superficie dorsal generalmente opaca . . . . . . . . . . . . . . . . . . 10

10. Maza antenal de los machos tan larga o ligeramente más larga como los cinco artejos precedentes . . . . . . . . . . . . . . . . . 11

10'. Maza antenal de los machos notablemente más larga que los cinco artejos

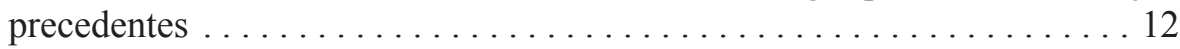



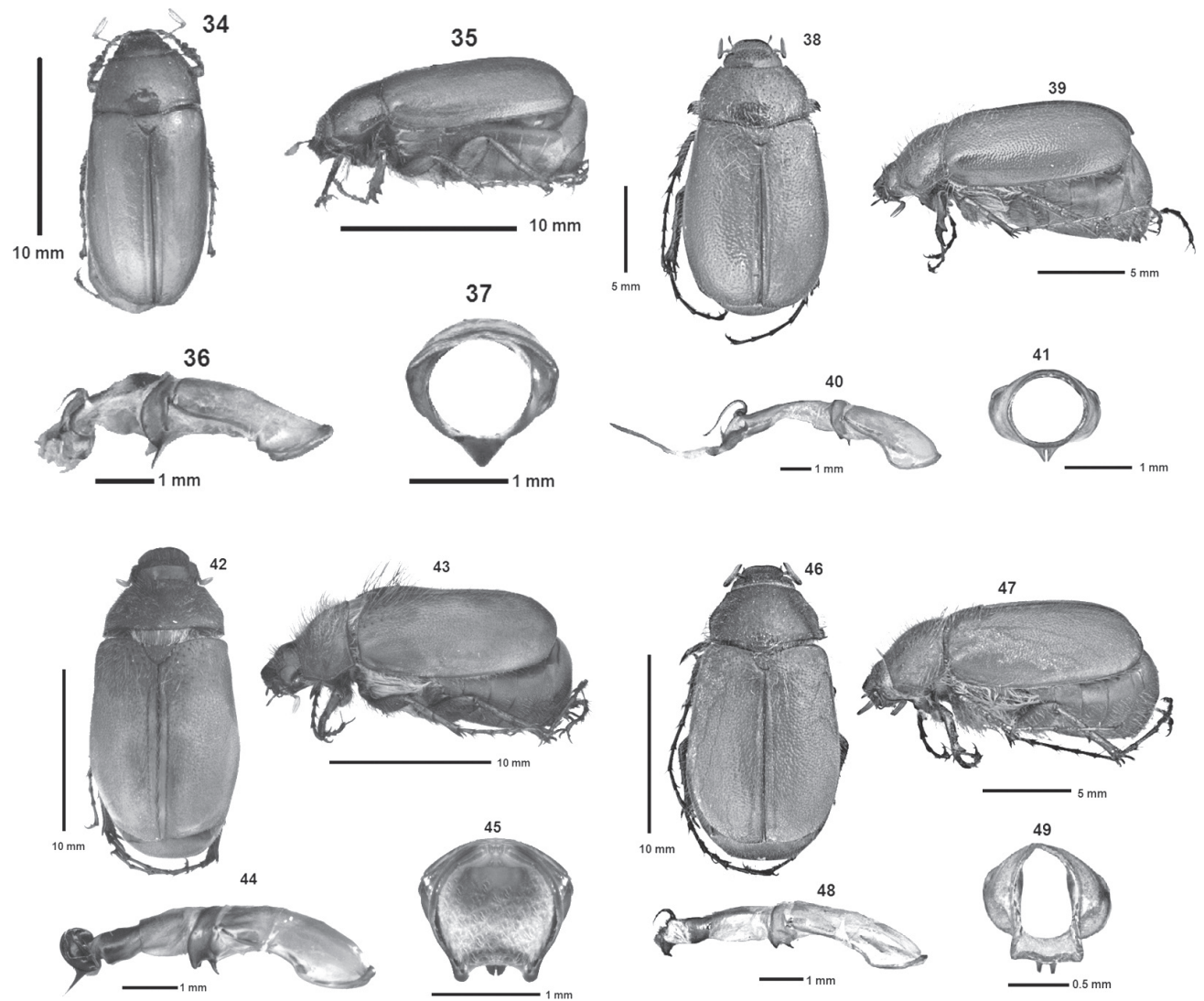

43
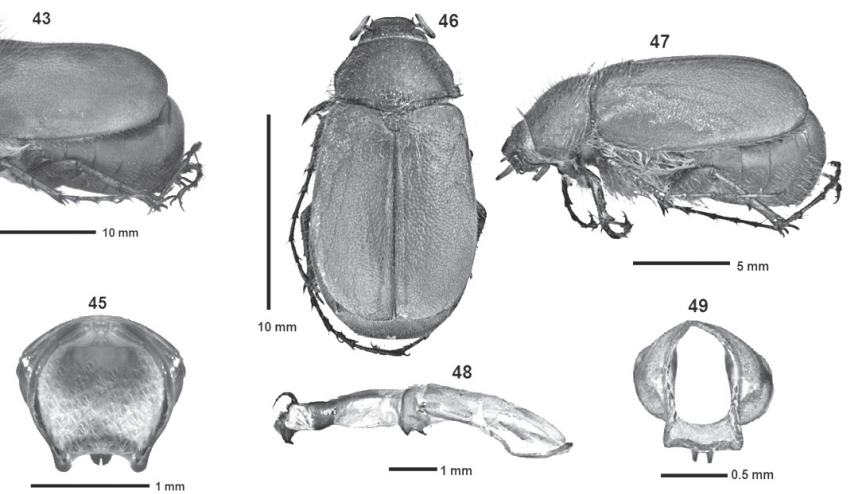

Figuras 34-49. Especies de Phyllophaga en Xoxocotlán: P. ravida macho, 34) vista dorsal, 35) vista lateral, 36) aspecto lateral de genitalia completa, 37) aspecto distal parámeros. $P$. lenis macho, 38) vista dorsal, 39) vista lateral, 40) aspecto lateral cápsula genital completa, 41) aspecto distal parámeros. $P$. vetula macho, 42) vista dorsal, 43) vista lateral, 44) aspecto lateral cápsula genital completa, 45) aspecto distal parámeros. $P$. misteca macho, 46) vista dorsal, 47) vista lateral, 48) aspecto lateral cápsula genital completa, 49) aspecto distal parámeros.

11. Penúltimo esternito abdominal sin área granulosa notable. Superficie dorsal setífera (Figs. 38 y 39). Placa anal masculina con un proceso bidentado en el borde anterior. Parámeros con una pequeña proyección bidentada ventral en los ápices, sin proyecciones laterales (Fig. 41). Ápice del edeago con un flagelo largo, recurvado y espinoso (Fig. 40) ...... P. (Phyllophaga) lenis

11 '. Penúltimo esternito con un área granulosa pequeña. Superficie dorsal opaca (Fig. 42). Abundantes sedas largas en la base de los élitros, pronoto y la región pleuroventral (Fig. 43). Parámeros con los ápices cortos, contiguos, 
con una pequeña proyección ventral bidentada orientada caudalmente y proyecciones laterales anchas y separadas (Fig. 45). Ápice del edeago con un flagelo esclerosado asimétrico recurvado (Fig. 44). Longitud del cuerpo:

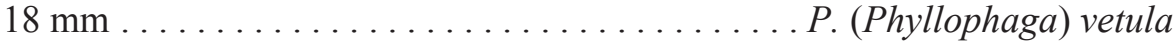

12. Penúltimo esternito abdominal con un área granulosa pequeña. Placa anal con un proceso bidentado en el borde anterior. Sedas cortas esparcidas en pronoto y base de élitros (Figs. 46 y 47). Parámeros con proyección bidentada en los ápices orientada caudalmente, con proyecciones laterales cortas, anchas y separadas (Figs. 48 y 49). Edeago con flagelo apical corto curvado y un proceso setífero (Fig. 48). Longitud corporal: $16 \mathrm{~mm}$......P. (Phyllophaga) misteca

12 '. Penúltimo esternito abdominal con un área granulosa amplia y muy notable. Superficie con sedas esparcidas en pronoto y base de élitros. Coloración parda amarillenta (Figs. 50 y 51). Ápice del edeago con una proyección dorso-apical curva con muchas sedas cortas y gruesas (Fig. 52). Parámeros cortos, con los ápices convergentes con proyección bidentada y que exhiben proyecciones laterales afiladas, proyectadas ventralmente (Fig. 53) ......................... (Phyllophaga) integriceps

\section{DISCUSIÓN}

Riqueza de especies. El valor de riqueza de especies encontrada en este estudio (13) se encuentra situada en el extremo superior de las muestras del territorio nacional analizadas por Morón (2006b) quién concluyó que el número de especies de una localidad no parece tener una estrecha relación con aspectos climáticos, altitudinales o latitudinales, sino más bien está relacionado con el tipo de hábitat y el estado de conservación o grado de perturbación existente en él. El número de especies también parece ser una consecuencia de dos fenómenos: un estado de clímax de una comunidad de Phyllophaga, o un estado de transición en la sucesión de una comunidad de dicho género. Los resultados encontrados en Xoxocotlán, una zona perturbada por el monocultivo del maíz, el pastoreo extensivo y el cambio de uso de suelo, coinciden con el segundo comportamiento donde teóricamente se encuentra un alto índice de predominio de una especie, con la mayoría de las especies restantes con amplia distribución y donde también es posible encontrar una o dos especies endémicas o con distribución restringida.

Existen pocos casos documentados acerca de la diversidad específica de Phyllophaga en Oaxaca, Bravo-Mosqueda (2003) y Ramírez-Ponce et al. (2009), donde en el primer caso se observa un número de especies bajo (5) a pesar de que parte del estudio se llevó a cabo en los Valles Centrales de Oaxaca. En el segundo estudio se observa una tendencia similar a lo referido aquí, a pesar de las condiciones ambientales totalmente distintas. Por lo anterior, es complicado predecir la diversidad de una comunidad de Phyllophaga en los ambientes oaxaqueños. 


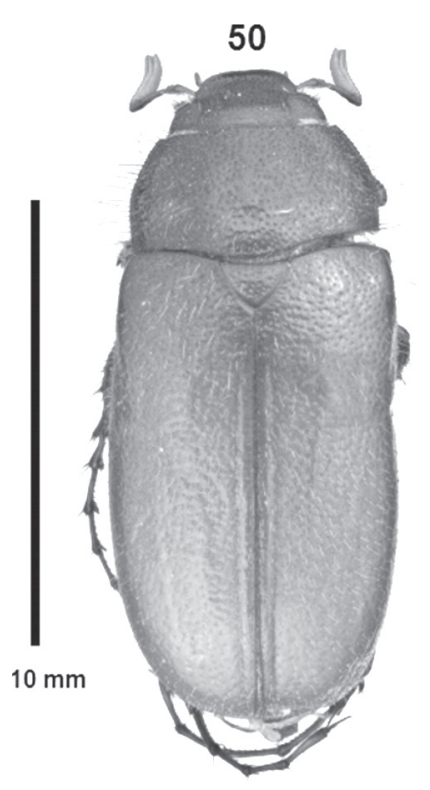

52

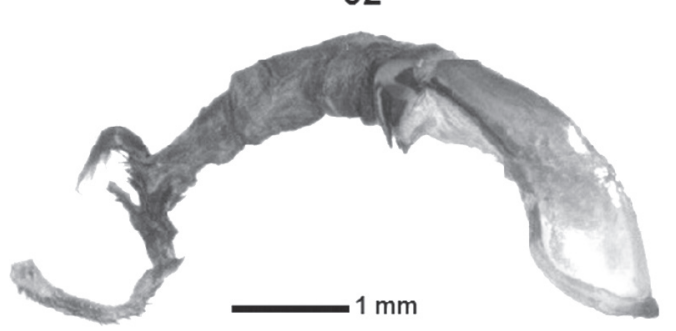

\section{1}

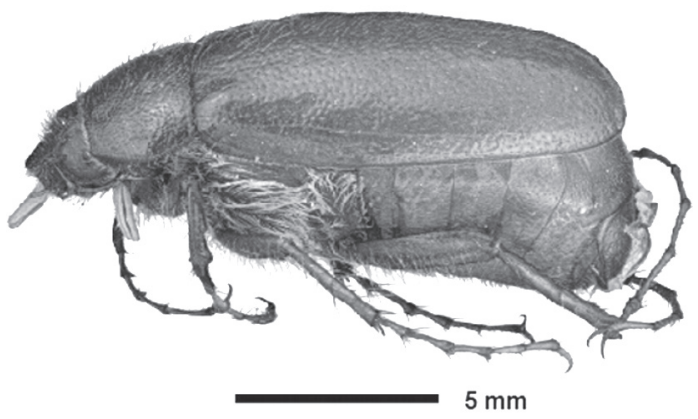

53

Figuras 50-53. Phyllophaga integriceps: 50) vista dorsal, 51) vista lateral, 52) aspecto lateral de genitalia completa, 53) aspecto distal parámeros.

Composición de la comunidad de Phyllophaga. Está documentado que casi en cualquier localidad de México es posible encontrar entre 8 a 16 especies de este género, donde una, típicamente, tiene un marcado predominio sobre las demás. También es posible señalar que la presencia de la especie predominante en cada localidad está determinada por su linaje o filiación. Pero explicar la presencia del resto especies o grupos de especies que componen la comunidad de Phyllophaga de una localidad no es sencillo, si se toma en cuenta el solapamiento natural de los grupos específicos en las regiones del país entre otros factores importantes a considerar. He aquí una breve interpretación de la presencia de especies o grupos de especies en Xoxocotlán:

Phyllophaga obsoleta es la única especie del grupo del mismo nombre presente en esta comunidad. El linaje al que pertenece posiblemente se originó en el Núcleo 
Centroamericano por ello no resulta difícil encontrarla en las montañas húmedas de México y América Central. Sin embargo, Morón (2006a) en un estudio detallado del grupo encontró que se distribuye desde el oeste, centro, noroeste y sureste de México, pudiendo habitar bosques tropicales y subtropicales, caducifolios, bosque mesófilo de montaña, encinares, bosque de pino y encino, matorrales, terrenos cultivados y plantaciones ubicadas entre los 30 y 2,667 m. de altitud. El mismo estudio revela variaciones en la forma las antenas, pronoto, los últimos esternitos, la placa pigidial y la genitalia lo que hace suponer que muchas de estas variaciones sean consecuencia de la facilidad con que esta especie se adapta a las perturbaciones naturales o inducidas, lo que le ha permitido dispersarse de una comunidad a otra, incluso invadiendo áreas que son restrictivas para otras especies del género, colocándola como una de las especies con más amplia distribución en el país.

Las especies del grupo anodentata ( $P$. lenis, $P$. vetula, $P$. misteca y $P$. integriceps) y del grupo ravida ( $P$. ravida) proliferan en climas templados a cálidos, desde tierras altas $(2500 \mathrm{msnm})$ hasta los litorales (aunque son más abundantes y diversas entre 1500 a $2500 \mathrm{msnm}$ ), pero prefieren ambientes menos húmedos, que sugieren una evolución en los ambientes de mediana elevación en las vertientes occidentales de México. Debido a lo anterior no es extraño que estas especies estén presentes en los Valles Centrales, y que su presencia sea notablemente predominante como es el caso de $P$. lenis en este estudio. Las mismas observaciones aplican al caso de $P$. ravida. En el estudio de la composición de comunidades de Phyllophaga en México, Morón (2006b), se observa que si aparece una especie del grupo anodentata invariablemente aparecerá una especie del grupo ravida.

Phyllophaga scabripyga y $P$. chiapensis son especies que pertenecen al grupo latipes, cuyo posible origen sea el Itsmo de Tehuantepec y están presentes en ambientes con distintos grados de humedad pero calurosos. Su presencia en los Valles Centrales oaxaqueños es un tanto rara, dado que el clima de esta región es templado, aunque es válido reconocer que últimamente la temperatura promedio ha incrementado significativamente, lo que posiblemente esté propiciando que estas especies ocupen territorios que hasta hace poco no le eran propicios.

Phyllophaga macrocera y $P$. nubipennis son especies que están incluidas en el grupo macrocera cuyas especies se distribuyen entre la porción central del Eje Neovolcánico, Córdoba, Veracruz y el Altiplano Oaxaqueño. Habitan en bosques tropicales caducifolios, pino, encino y matorrales secundarios ubicados entre los 200 a $2900 \mathrm{msnm}$. La distribución de las especies del grupo macrocera encontradas en Xoxocotlán parece estar restringida al Altiplano Oaxaqueño sobre todo $P$. nubipennis quien sólo está citada para Oaxaca, por lo que pueden considerarse comunes pero restringidas a esta área.

Phyllophaga cinnamomea y $P$. parvisetis son especies de talla grande del grupo rorulenta cuyo punto de origen parecen ser los bosques tropicales de diverso tipo del 
sureste de México y Centroamérica, ubicados entre el nivel del mar y los $1000 \mathrm{~m}$ de altitud, ya que la distribución de las especies mexicanas del grupo al que pertenecen se limita a este tipo de condiciones (Morón 2006b). Su presencia en los Valles Centrales es una novedad promovida por el incremento de la temperatura.

Phyllophaga porodera pertenece al grupo del mismo nombre, su presencia es común en encinares, bosque mesófilo de montaña y matorrales xerofilos ubicados entre los 300 y $2100 \mathrm{~m}$ de altitud. Las condiciones ecológicas que ofrecen los Valles Centrales son propicias para ella.

AgRAdecimientos. Se agradece a Jorge A. Valdez Carrasco del Colegio de Postgraduados, Campus Montecillos y Javier Ruiz de la Cruz del CIIDIR-IPN Oaxaca por su valioso apoyo en la toma y edición de las imágenes de las especies. Roberto Arce Pérez y César V. Rojas Gómez del INECOL Xalapa, colaboraron en aspectos técnicos de este trabajo.

\section{LITERATURA CITADA}

Aragón, A. \& Morón, M. A. 2004. Descripción de las larvas de tres especies de Phyllophaga (Coleoptera: Melolonthidae: Melolonthinae) del Valle de Puebla, México. Folia Entomológica Mexicana, 43: 295-306.

Aragón, A., Morón, M. A., López-Olguín, J. F. \& Cervantes-Peredo, L. M. 2005. Ciclo de vida y conducta de adultos de cinco especies de Phyllophaga Harris, 1827 (Coleoptera: Melolonthidae: Melolonthina). Acta Zoológica Mexicana (n.s.), 21: 87-99.

Bravo-Mosqueda, E. 2003. Gallina ciega, diagnóstico de la situación que guarda en las regiones de la Mixteca y los Valles Centrales de Oaxaca, pp. 269-282. In: Aragón, G. A., M. A. Morón \& A. J. Marín (Eds.). Estudios Sobre Coleópteros del Suelo en América. Publicación especial de la Benemérita Universidad Autónoma de Puebla.

Hernández-Cruz, J. 2010. Caracterización y evaluación de las especies de Phyllophaga Harris (Coleoptera: Melolonthidae) en Santa Cruz Xoxocotlán, Oaxaca. Tesis inédita. CIIDIR-IPN Unidad Oaxaca, México.

Morón, M. A. 1986. El género Phyllophaga en México. Morfología, distribución y sistemática supraespecifica (Insecta: Coleoptera). Publicación 20. Instituto de Ecología, México. 344 pp.

Morón, M. A. 2003. Diversidad, distribución e importancia de las especies de Phyllophaga Harris en México (Coleoptera: Melolonthidae), pp. 1-27. In: Aragón, G. A., M. A. Morón \& A. J. Marín (Eds.). Estudios Sobre Coleópteros del Suelo en América. Publicación especial de la Benemérita Universidad Autónoma de Puebla.

Morón, M. A. 2006a. Revisión de las especies de Phyllophaga (Phytalus) grupos obsoleta y pallida (Coleoptera: Melolonthidae: Melolonthinae). Folia Entomológica Mexicana, 45 (Supl. 1): 1-104.

Morón, M. A. 2006b. Composición de comunidades de Phyllophaga en México (Coleoptera: Melolonthidae: Melolonthinae), pp. 11-36. In: Castro-Ramírez, A. E., M. A. Morón \& A. Aragón (Eds.). Diversidad, Importancia y Manejo de Escarabajos Edaficolas. Publicación especial de El Colegio de la Frontera Sur, la Fundación PRODUCE Chiapas, A.C. y la Benemérita Universidad Autónoma de Puebla, México.

Morón, M. A. 2008. Phyllophaga (Phytalus) munizi, una nueva especie mexicana del grupo senicula (Coleoptera: Melolonthidae: Melolonthinae). Dugesiana, 15: 141-144. 
Morón, M. A. 2012. Phyllophaga (Listrochelus) gonzalffteri, nueva especie de Oaxaca y Puebla, México (Coleoptera: Melolonthidae: Melolonthinae). Dugesiana, 18: 161-168.

Morón, M. A. 2010. Diversidad y distribución del complejo "gallina ciega" (Coleoptera: Scarabaeoidea), pp. 41-63. In: Rodríguez del Bosque L. A. \& M. A. Morón (Eds.). Plagas del suelo. Publicación especial del Colegio de Postgraduados, Instituto Nacional de Investigaciones Forestales, Agrícolas y Pecuarias Chiapas, Universidad Autónoma Chapingo y Mundi Prensa México S.A. de C.V.

Morón, M. A. \& Hernández-Cruz, J. 2013. Nuevas especies de Phyllophaga Harris (Coleoptera: Melolonthidae: Melolonthinae) de la Mixteca Oaxaqueña, México. Dugesiana, 20: 55-59.

Morón, M. A., Hernández-Rodríguez, S. \& Ramírez-Campos, A. 1996. El complejo "gallina ciega" (Coleoptera: Melolonthidae: Melolonthiane) asociado a la caña de azúcar en Nayarit, México. Folia Entomológica Mexicana, 98: 1-44.

Morón, M. A., Hernández-Rodríguez, S. \& Ramírez-Campos, A. 1999. Description of immature stages of Phyllophaga (Triodonyx) lalanza Saylor (Coleoptera: Melolonthidae: Melolonthiane). PanPacific Entomologist, 75: 153-158.

Morón, M. A., Rodríguez-del Bosque, L. A., Aragón, A. \& Ramírez-Salinas, C. 2010 a. Biología y hábitos de coleópteros escarabaeoideos, pp. 65-82. In: Rodríguez del Bosque L. A. \& M. A. Morón (Eds.). Plagas del suelo. Publicación especial del Colegio de Postgraduados, Instituto Nacional de Investigaciones Forestales, Agrícolas y Pecuarias Chiapas, Universidad Autónoma Chapingo y Mundi Prensa México S.A. de C.V.

Morón, M. A., Hernández-Rodríguez, S. \& Ramírez-Campos, A. 2010b. Gallina ciega en Nayarit, pp. 285-298. In: Rodríguez del Bosque L. A. \& M. A. Morón (Eds.). Plagas del suelo. Publicación especial del Colegio de Postgraduados, Instituto Nacional de Investigaciones Forestales, Agrícolas y Pecuarias Chiapas, Universidad Autónoma Chapingo y Mundi Prensa México S.A. de C.V.

Morón, M. A. \& Nogueira, G. 2012. Phyllophaga (Phyllophaga) josepalaciosi (Coleoptera: Melolonthidae: Melolonthinae) nueva especie del sur de Oaxaca, México. Dugesiana, 19: 69-72.

Morón, M. A. \& Terrón, R. 1988. Entomología Práctica. Publicación 22. Instituto de Ecología. A.C. México D.F. 504 pp.

Morón, M. A. \& Woodruff, R. E. 2008. Three new species of Phyllophaga from Mexico (Coleoptera: Scarabaeidae: Melolonthinae). Florida Entomologist, 91: 198-204.

Ramírez-Salinas, C., Morón, M. A. \& Castro-Ramírez, A. 2000. Descripción de los estados inmaduros de seis especies de Phyllophaga (Coleoptera: Melolonthidae: Melolonthinae) de la región Altos de Chiapas, México. Folia Entomológica Mexicana, 109: 73-106.

Ramírez-Ponce, A., Allende-Canseco, J. \& Morón, M. A. 2009. Fauna de Coleópteros Lamelicornios de Santiago Xiacuí, Sierra Norte, Oaxaca, México. Acta Zoológica Mexicana (n.s.), 25: 323-343. 